\title{
Impact of COVID-19 Restrictions on the Social-Emotional Wellbeing of Preschool Children and Their Families
}

\author{
Tanja Linnavalli *(D) and Mirjam Kalland \\ Faculty of Educational Sciences, University of Helsinki, 00014 Helsinki, Finland; mirjam.kalland@helsinki.fi \\ * Correspondence: tanja.linnavalli@helsinki.fi
}

check for updates

Citation: Linnavalli, T.; Kalland, M. Impact of COVID-19 Restrictions on the Social-Emotional Wellbeing of Preschool Children and Their Families. Educ. Sci. 2021, 11, 435. https://doi.org/10.3390/

educsci11080435

Academic Editor: Eila Jeronen

Received: 6 July 2021

Accepted: 15 August 2021

Published: 17 August 2021

Publisher's Note: MDPI stays neutral with regard to jurisdictional claims in published maps and institutional affiliations.

Copyright: (c) 2021 by the authors. Licensee MDPI, Basel, Switzerland. This article is an open access article distributed under the terms and conditions of the Creative Commons Attribution (CC BY) license (https:/ / creativecommons.org/licenses/by/ $4.0 /)$.

\begin{abstract}
In the spring of 2020, as a result of the lockdown caused by the COVID-19 pandemic, many children dropped out of daycare and early education in Finland, and parents had to balance work and childcare for months. The wellbeing of families during the lockdown has been studied to some extent, but few studies have focused on children under school age. In May 2020, we sent a survey to the 82 families originally recruited in our study on supporting social-emotional development in early childhood education units, which had been interrupted by the pandemic. Twenty families responded to questionnaires about the impacts of the lockdown on the wellbeing of the children and their parents. Parents reported a decline in children's prosocial behavior compared to the time before the pandemic and assessed that the children who stayed at home were lonelier than children who remained in daycare. Otherwise, being at home or in care was not associated with children's physical or mental wellbeing. Parents had experienced increased mental strain and increased problems in marital relationships and the disruption of children's participation in daycare was associated with deterioration in the parent-child relationship. Due to the small sample size, these results should be interpreted with caution.
\end{abstract}

Keywords: COVID-19; early childhood education; social-emotional wellbeing; families

\section{Introduction}

UNESCO estimates that the pandemic has affected the lives of around 1.6 billion school children in 190 countries [1] and globally, an average of two-thirds of the school year has been missed due to pandemic-related school closures [2]. In addition, the pandemic has affected the lives of an estimated 93 million children in early childhood education and pre-school in 34 countries [3]. Thus, the pandemic is not only a health crisis, but also a crisis that will affect the possibility of reaching the United Nations Sustainability Goals, especially SDG 4 (to ensure inclusive and equitable quality education and promote lifelong learning opportunities for all), as has been pointed out in a recent review [4].

In Finland, the COVID-19 pandemic locked down society. The schools and, in part, also early childhood education, closed in the spring of 2020. Early childhood education and care (ECEC) centers were kept open, but parents were advised to keep children at home if possible. In addition, offices were closed and people moved rapidly to remote work. People were advised to avoid social contact and especially to protect elderly people, such as grandparents. According to the Regional State Administrative Agency, only 27\% of children participated in municipal early childhood education, in comparison with normal numbers [5].

The effects of remote education and work on families have already been researched both in Finland and internationally, but most of the research has focused on school-age children and their families. Little is known about the effects of the current pandemic on the families and wellbeing of small children, although articles leaning on former knowledge about isolation and exceptional circumstances have been published (see e.g., [6-8]). However, there are some studies focusing on the mental effects of the COVID-19 pandemic on small children's families, based on data collected in spring 2020. 
According to the University of Jyväskylä's Parent Resource and Load Factor's (VoiKu) pandemic-related survey conducted April-May $2020(\mathrm{~N}=1105)$ in Finland, the effects of the crisis on the wellbeing of parents have become polarized. While $54 \%$ of respondents saw the exceptional period as gloomy and hopeless, $44 \%$ saw the situation as bright and hopeful. Based on open-ended responses, parents' perceptions of the situation had been influenced by, among other things, financial difficulties, low support from ECEC or school, and difficulty in reconciling work and family life [9]. On the other hand, $35.7 \%$ of the respondents to the national FinSote survey in the autumn of $2020(N=17,000)$ felt that hope for the future had decreased and $21.4 \%$ that their economic situation had deteriorated at least slightly [10].

The U.S. studies about the wellbeing of parents of families with children during isolation found that parents' mental health and wellbeing deteriorated, and their moods were negative more often than before [11,12]. Patrick and colleagues' study [12] revealed that part of the parents of children aged $0-5$ years $(\mathrm{N}=1011)$ felt that their physical and mental wellbeing had deteriorated ( $20.8 \%$ and $31.4 \%$, respectively). The stated questions were very general ("Has your own physical health gotten better or worse?" and "Has your own mental health gotten better or worse?") and did not differentiate between separate aspects of physical or mental health. The follow-up study by Gassman-Pines et al. [11] conducted in the United States in February-April 2020, showed that the mood of parents $(\mathrm{N}=645)$, assessed with a question "How much of the time today did you feel fretful, angry, irritable, anxious, or depressed?" was more negative during the pandemic than before it. Furthermore, it was strongly correlated with the adversities caused by the pandemic (unemployment, declining income, illness, increased burden of childcare): the more adversities, the less wellbeing. Due to the study design, the results of Gassman-Pines and colleagues give quite convincing evidence on the decline in parents' mood during the first restrictions in spring 2020. In their take on the matter, Prime, Wade and Brown [7] proposed that parents' negative mood, anxiety, and stress during the pandemic affect children's wellbeing, and such results have already been found [13].

The wellbeing of young children in the crisis caused by the pandemic has also been studied. In addition to results concerning the parents themselves, Patrick and colleagues found also that $14 \%$ of parents estimated that the mental health of their children under the age of 18 had worsened. Regarding children under the age of 5 , parents rated their physical $(2.5 \%)$ and mental $(17.8 \%)$ wellbeing as having worsened under isolation (Patrick et al., 2020). As with the questions probing parents' wellbeing, the questions concerning children were also very general ("Has the physical health of any of your children gotten better or worse?" and "Has the behavioral health of any of your children gotten better or worse?"), and thus does not allow inspecting any specific aspects of children's mental health and their behavior during the restrictions. Partly contradicting this result, the follow-up study by Gassman-Pines and colleagues with 645 parents working in the service sector and having 2-7-year-old children, showed that although parent wellbeing deteriorated during the pandemic containment, the children's mood did not, and behavioral disorders did not increase compared to the time before the pandemic in the spring of 2020. Parents estimated that the deterioration in children's mental state and increased behavioral problems were associated with illness in the family and the increased burden of childcare [11]. Children's mood was assessed with question "How much did your child appear to be sad or worried today?" and behavior with question "How much was your child uncooperative today?", which is quite general in nature and does not give a possibility to differentiate between separate aspects of behavior.

In Spain during the period of severe mobility restrictions, a survey conducted in April 2020 on families of children aged 3 to $12(N=1123)$ showed that generally there was no change in children's emotional problems, conduct problems, or hyperactivity compared to the time before the restrictions. These were assessed with the 14 statements of the parental Strengths and Difficulties Questionnaire (SDQ) [14], with answer options modified to allow comparison with behavior before the lockdown (much less/somewhat 
less/no change/somewhat more/much more). However, a separate examination of the age groups revealed that parents estimated there to be a greater increase in conduct problems and hyperactivity in 3- to 6-year-old children than in school-age children. Furthermore, according to the study, anxiety experienced by parents had a negative effect on children's adjustment to the situation and their behavior [15]. The latter result is in line with a study conducted with a survey in Italy in April 2020: mothers $(\mathrm{N}=245)$ estimated an increase in emotional problems, conduct problems, and hyperactivity (assessed with SDQ) and self-regulatory problems (assessed with The Behavior Rating Inventory of Executive Functions-preschool version [16]), in their 2-5-year-old children compared to pre-pandemic times [17]. According to the research, an increase in these problems was linked to the sleep quality of both children and their mothers.

The wellbeing of children aged $2-5$ years $(N=54)$ during the pandemic was studied in Canada as well. Between April and June 2020, parents answered questions regarding their children's emotional problems, conduct problems, and hyperactivity, assessed with SDQ. These assessments were compared with similar assessments conducted 18 months earlier. With young children, such a long interval between the measurement points makes it impossible to rule out factors other than the pandemic having induced the observed change. Two-thirds $(66.7 \%)$ of parents reported that children are doing worse in at least one of these three dimensions (deteriorated: emotional problems $(31.5 \%)$, conduct problems $(29.6 \%)$, hyperactivity $(35.2 \%))$. However, about one third (31.5\%) estimated that children were doing better considering at least one of the measured traits (improved: emotional problems $(11.1 \%)$, conduct problems $(16.7 \%)$, hyperactivity $(14.8 \%))$. In addition, children aged 2-5 years accumulated fewer problems and got over them faster than the older age groups studied, suggesting that young children suffer less from changes in daily routines than school-age children and adolescents [18].

The results on the wellbeing of pre-school children in the early stages of the pandemic are thus in part contradictory. Regarding longitudinal studies, Gassman-Pines et al. [11] suggested that children's mood or cooperative behavior did not change but Cost et al. [18] showed that approximately one-third of the parents reported an increase in emotional problems, conduct problems, or/and hyperactivity, although overall, small children seemed more resilient that school-aged children. The two cross-sectional studies using SDQ [15,17], also point in different directions, particularly regarding emotional problems. Concerning conduct problems and hyperactivity, the studies are more in line, showing deterioration in small children as such or as compared to older children. However, as the study designs are cross-sectional, it seems possible that assessing children's behavior more negatively than before the pandemic is partly due to parents having to balance work and childcare at the same time.

How are young children and their families faring in Finland during the pandemicrelated restrictions? How is the wellbeing of parents related to the wellbeing of children and how has the children's absence from early childhood education affected their mutual wellbeing? These research questions and the research design emerged from a disrupted research project. In February 2020, we started a pilot research on promoting social-emotional development within ECEC, but the research was interrupted by the lockdown. However, we had already collected data from 82 families with 90 children. Thus, we decided to send new questionnaires to the families recruited for the original research to get a "before and during lockdown" assessment, with the lockdown as the unintended "intervention," as well as a cross-sectional assessment of the wellbeing of families during restrictions. The main questions of our present study are:

1. How did the lockdown during spring 2020 affect the social-emotional and physical wellbeing of the children and their parents?

2. Was there an association between participating in ECEC and the wellbeing of children and parents? 


\section{Materials and Methods}

All participating families were initially recruited in January 2020 to participate in the SAGA study, which examines socio-emotional and linguistic development with 3-5-year-old children in Swedish-speaking municipal kindergartens in the Helsinki metropolitan area. The study was approved by the University of Helsinki Ethical Review Board in the Humanities and Social and Behavioural Sciences (65/2019), in Helsinki, Finland, and was carried out in accordance with the committee's guidelines and regulations, as well as with those of the Helsinki Declaration. In May 2020, these 82 families (90 children in total) were sent the Strengths and Difficulties Questionnaire (SDQ) [14], the KINDL questionnaire for the parents of 3 to 6-year-old children [19] and an additional questionnaire with pandemic-related questions. The parents had already given their informed consent about the participation of their children in connection with the original recruiting. In the original study, the children were further asked orally if they wanted to participate in the study, and if they declined they were excluded from the study. However, the data reported here were not collected via testing but with questionnaires targeted to parents, who were free to choose whether to answer them or not.

We asked both parents to respond to the questionnaires, but only in one family did both parents respond to them. Regarding children, at least one of the questionnaires was returned for a total of 25 children (24 KINDL and Pandemic questionnaires, 24 SDQ questionnaires). The KINDL and the pandemic-related questionnaire was answered by 21 parents (18 mothers, 3 fathers) out of 20 families with a total of 24 children participating in the study. Of these children, 22 had previously had a background information questionnaire filled in by their parents. Parents answered the SDQ on behalf of 24 children, of whom 22 had also had the SDQ answered at the beginning of the SAGA study in February 2020. For a more detailed representation of the returned questionnaires concerning children, see Table S1 in Supplementary Materials.

\subsection{The Child Strengths and Difficulties Questionnaire}

The Child Strengths and Difficulties Questionnaire (SDQ) [14] is an internationally widely used questionnaire for social-emotional development. Usually a parent or a teacher evaluates the child using 25 statements. These statements make up five different factors that are formed by summing the scores of the response sections together: emotional problems, peer relationship problems, hyperactivity, conduct problems, and prosocial behavior. All statements are answered on a scale of $0-2(0=$ Not valid; $1=$ Somewhat true; $2=$ Definitely true), and the questionnaire is mainly used in clinical work to find symptomatic children. In this study, the factors were formed by calculating averages from separate sections instead of the sum. This enables the comparison of the group means of the factors and the answer options.

\subsection{Kiddy KINDL Questionnaire}

The Kiddy KINDL questionnaire [19] is a tool for assessing health-related quality of life in children and adolescents between 3 and 17 years of age. The assessment differs slightly according to the age group and can be completed by either the child or adolescent themselves or by their parents. The questionnaire includes sections assessing a child's physical wellbeing, emotional wellbeing, self-esteem, relationship with the parent, social contacts, and enjoyment and coping in school. The parental version also contains 22 additional questions entitled "Some important questions", mostly assessing the child's mood.

In our study, the statements concerning social contacts and enjoyment and coping in school were left out, and the response options of the KINDL questionnaire were modified to meet the pandemic circumstances. All multiple-choice statements started with "During the last weeks of quarantine ..." The answer options were $0=$ never/much less often than before, $1=$ less often than before, $2=$ as often as before, $3=$ more often than before, $4=$ much more often than before. 
After receiving the KINDL questionnaires from the parents, the sum variables were created in accordance with the KINDL guidelines. However, if the reliability between the statements of the sum variable according to KINDL was poor, individual statements that would impair internal consistency were omitted. In addition, due to the poor overall reliability between the four items in emotional wellbeing, this section was left out from the analyses, excluding one individual item used as a separate variable in the analyses (see below). The sum variables were formed by averaging the scores of the statements.

The sum variable for a child's physical symptoms was created by averaging three statements in KINDL's physical wellbeing subscale ("My child felt sick"; "My child had headache or tummy-ache"; "My child was tired and worn-out") and the sum variable for a child's self-esteem by averaging three statements in KINDL's self-esteem subscale ("My child was proud of him/herself"; "My child felt on top of the world"; "My child felt pleased with him-/herself"). The child's negativity was created by averaging eleven statements in the KINDL's "some important questions" subscale ("My child was moody and whined a lot"; "My child felt under pressure"; "My child kept bursting into tears"; "My child was easily distracted and absent-minded"; "I had to scold my child"; "My child had problems with teachers, kindergarten staff or other child-minders"; "My child was nervous and fidgety"; "My child complained of being in pain"; "My child became dissatisfied easily"; "My child cried bitterly"; "My child lost his temper quickly"). The sum variable for the parent-child relationship was originally created by averaging the three statements in KINDL's family subscale ("My child got on well with us as parents"; "We quarreled at home" (reversed scale); "My child felt that I was bossing him/her around" (reversed scale)). However, as the internal consistency of the created sum variable was low and the individual variable "I managed to show patience and understanding towards my child" from the "Some important questions" subscale correlated highly with parent-child relationship in the preliminary analysis, we added it to the sum variable.

In addition, one individual item in KINDL was used as a separate variable in the analyses: "My child felt alone" from the emotional wellbeing subscale.

\subsection{Pandemic-Related Questionnaire}

The pandemic-related questionnaire asked the parents about the arrangements in childcare and working life, the financial situation of the family, the state of the parents marital relationship and whether the exceptional period had changed their relationship with their children. In addition, the wellbeing of the parents was surveyed with a sum variable mental strain averaged over eleven items ("Have you during the exceptional period: worried about the situation in general; worried about your family's finances; been concerned about the future in general; feared that someone in your family would get sick; feared that someone close would get sick; felt depressed or low-spirited; experienced work-related stress; experienced family-related stress; felt exhausted; been well (reversed scale); felt irritated by your family members"). The answer options were $0=$ Not at all, $1=$ Less often than before, $2=$ As often as before, $3=$ More often than before, $4=$ Much more often than before. The pandemic-related questions are displayed in Questionnaire S2 in Supplementary Materials.

In addition to aforementioned questionnaires we used background questionnaires collected before the pandemic.

The analyses were conducted with SPSS 25 (IBM Corporation, Armonk, NY, USA). The alpha level was set at $p \leq 0.05$.

\section{Results}

\subsection{Background}

Of the 21 parents who responded to the crisis survey, 2 had upper secondary education, 4 had a bachelor's degree, 12 had a master's degree, and 1 had a doctorate or licentiate degree. Education data were missing for two respondents. The gross monthly income of households (20) ranged from $€ 2000$ to $€ 4000$ ( 3 households), $€ 4000$ to $€ 6000$ (1), $€ 6000$ to 
$€ 8000$ (7) and more than $€ 8000$ (9) $(\mathrm{M}=4.2, \mathrm{MD}=4, \mathrm{SD}=1.1$, on a scale of 1 to 5). The financial situation had remained the same in seventeen families, slightly improved in one, and slightly (1) or significantly (1) deteriorated in two families $(\mathrm{M}=1.9, \mathrm{MD}=2, \mathrm{SD}=0.55$; scale $0=$ Much worse than before, $2=$ Same as before, $4=$ Much better than before). The level of education and income of the respondents did not differ significantly from that of the families who answered these questions only in the original research project (education: $\mathrm{n}=43$ and income: $\mathrm{n}=45$ ) but did not participate in the pandemic-related study (education: $\mathrm{t}(62)=-1.279, p=0.206$; income: $\mathrm{t}(60)=-1.524, p=0.133)$.

\subsection{Social-Emotional Wellbeing of the Children}

Parents estimated in the Strengths and Difficulties Questionnaire that children on average had very few emotional problems $(\mathrm{M}=0.39, \mathrm{MD}=0.20, \mathrm{SD}=0.37$; scale $0=$ Not valid; $1=$ Somewhat true; 2 = Definitely true), conduct problems $(\mathrm{M}=0.40, \mathrm{MD}=0.40$, $\mathrm{SD}=0.29)$ or peer relationship problems $(\mathrm{M}=0.40, \mathrm{MD}=0.40, \mathrm{SD}=0.32)$. On average, slightly more hyperactivity was reported than other problems $(\mathrm{M}=0.76, \mathrm{MD}=0.70$, $\mathrm{SD}=0.53)$, and on average children's prosocial skills were assessed to be high $(\mathrm{M}=1.45$, $\mathrm{MD}=1.60, \mathrm{SD}=0.41)$. The majority of children did not suffer from emotional problems (17), conduct problems (17), or peer relationship problems (17) at all or almost at all (i.e., scoring lower than 0.5 ). Two children clearly (scoring 1.5 or higher) and 14 children to some extent (scoring between 0.5 and 1.4) showed symptoms of hyperactivity. Parents of all children estimated that their child behaved mostly (14) or at least to some extent (10) prosocially (scoring 1.5 or higher and scoring between 0.5 and 1.5, respectively). Table 1 displays the descriptives for SDQ assessments before and during the pandemic.

Table 1. The descriptives for the Strengths and Difficulties Questionnaire before and during the restrictions due to pandemic. Scores correspond to the assessment scale of $0=$ Not applicable; $1=$ Somewhat valid; $2=$ Definitely true. $S D=$ standard deviation, $\min =$ minimum scores obtained, $\max =$ maximum scores obtained.

\begin{tabular}{|c|c|c|c|c|c|c|}
\hline & \multicolumn{3}{|c|}{$\begin{array}{l}\text { Before Restrictions } \\
\qquad(\mathrm{N}=22)\end{array}$} & \multicolumn{3}{|c|}{$\begin{array}{l}\text { During Restrictions } \\
\qquad(\mathrm{N}=24)\end{array}$} \\
\hline & Mean (SD) & Median & Min; Max & Mean (SD) & Median & Min; Max \\
\hline emotional problems & $0.36(0.32)$ & 0.20 & $0 ; 1.0$ & $0.39(0.37)$ & 0.20 & $0 ; 1.4$ \\
\hline conduct problems & $0.34(0.29)$ & 0.40 & $0 ; 0.8$ & $0.40(0.29)$ & 0.40 & $0 ; 1.0$ \\
\hline hyperactivity & $0.80(0.52)$ & 0.80 & $0 ; 2.0$ & $0.76(0.53)$ & 0.70 & $0 ; 2.0$ \\
\hline peer relationship problems & $0.35(0.30)$ & 0.20 & $0 ; 1.2$ & $0.40(0.32)$ & 0.40 & $0 ; 1.2$ \\
\hline prosocial skills & $1.58(0.35)$ & 1.60 & $0.80 ; 2.0$ & $1.45(0.41)$ & 1.60 & $0.6 ; 2.0$ \\
\hline
\end{tabular}

Due to the small sample size ( $\mathrm{n}=22$ for completing both assessments), the comparison of the SDQ assessments completed before and during the restrictions was made using the pairwise Wilcoxon signed ranks test. Parents estimated that children's prosocial skills were worse during the lockdown than before the lockdown $(Z=-2.433, p=0.015)$. In the other measured characteristics (emotional problems, conduct problems, hyperactivity, and peer relationship problems), there were no differences between the two time points.

\subsection{Relationships between a Child's Physical Symptoms, Self-Esteem, Negative Mood, and Loneliness}

Regarding the KINDL questionnaire, the Cronbach's alpha ( $\alpha$ ) describing the internal consistency of the created sum variables was acceptable for a child's physical symptoms $(\alpha=0.772)$ and relatively high for self-esteem $(\alpha=0.809)$ and negativity $(\alpha=0.814)$. Parents reported that children had physical symptoms on average slightly less than before the crisis $(\mathrm{M}=1.07, \mathrm{MD}=1.33, \mathrm{SD}=0.89$; scale $0=$ Not at all, $1=$ Less often than before, $2=$ As often as before, $3=$ More often than before, $4=$ Much more often than before). Eight children had no symptoms of illness or fatigue at all, and nine had fewer than normal. Seven children had as many (5) or slightly more (2) symptoms than before. Self-esteem was estimated to have remained the same in the majority of children (19). Parents estimated 
that four children had either slightly (1) or much (3) better self-esteem than before, with one parent reporting slightly worse self-esteem for a child $(\mathrm{M}=2.13, \mathrm{MD}=2.00, \mathrm{SD}=0.35)$. On average, parents described their child to be slightly less negative than before $(\mathrm{M}=1.54$, $\mathrm{MD}=1.64, \mathrm{SD}=0.53$ ). Only five children were reported to have a slightly more negative mood, and as many as sixteen a slightly less negative mood than before. Children were reported to feel lonely on average slightly more frequently $(\mathrm{M}=2.13, \mathrm{MD}=2.00, \mathrm{SD}=1.04)$ than before. Eleven children were reported to feel lonely more often and eight as often as before. The remaining children were lonely less often than before (2) or not at all (3).

Changes in children's physical symptoms correlated strongly with changes in the children's negativity ( $\rho=0.627, p=0.001)$, so that the physically more disadvantaged children were also more negative in their mood. No other significant correlations emerged between self-esteem, physical symptoms, negativity, or feelings of loneliness. The correlations are shown in Table 2. Due to the small sample size, the correlations between variables were examined using Spearman's rank correlation coefficient.

Table 2. Spearman correlation coefficients between children's physical symptoms, self-esteem, negativity, and an assessment of child's loneliness.

\begin{tabular}{ccccc}
\hline & Physical Symptoms & Self-Esteem & Negativity & My Child Felt Alone \\
\hline physical symptoms & & - & - & - \\
self-esteem & 0.011 & & - & - \\
negativity & $0.627^{* *}$ & 0.044 & -0.253 & - \\
my child felt alone & -0.232 & 0.133 & \\
$* * * p<0.01$. & & &
\end{tabular}

\subsection{Mental Strain and the Parent-Child Relationship}

The Cronbach's alpha $(\alpha)$ describing the internal consistency of the created sum variables was acceptable for both parents' mental strain in the pandemic questionnaire $(\alpha=0.772)$ and the parent-child relationship in KINDL $\alpha=0.752$.

On average, parents had experienced slightly more mental strain than before $(\mathrm{M}=2.26$, $\mathrm{MD}=2.36, \mathrm{SD}=0.59$; scale $0=$ Not at all, $2=$ As often as before, $4=$ Much more often than before; a higher score indicating more mental strain). When asked directly in the pandemic questionnaire, the majority of parents (17) thought that the exceptional period had not changed the relationship between parent and child. Of the four who thought the relationship had changed, three thought it had improved. However, when the relationship between parent and child was measured by a KINDL sum variable parent-child relationship, which took into account, e.g., the number of quarrels, the parent-child relationship appeared to have deteriorated slightly compared to the pre-pandemic period $(\mathrm{M}=1.75, \mathrm{MD}=2, \mathrm{SD}=0.57$; scale $0=$ Much more seldom than before, $2=$ As often as before, $4=$ Much more often than before, a higher score indicating a better relationship). The mental strain was marginally significantly correlated with the quality of parent-child relationship $(\rho=-0.386, p=0.084)$, indicating that the more mental strain the parents experienced, the worse the relationship they had with their child.

\subsection{Associations between Participation in ECEC, Status of Marital Relationship, Parenting, and Child Wellbeing}

Between 18 March and 13 May 2020, which was the time frame of the pandemic survey, the children of fourteen families (17 children in total) were at home all or most of the time, and children of six families (seven children) attended early childhood education all or most of the time. Most parents worked at home (11) or were at home for other reasons (8). Out of the nineteen responding families, thirteen reported an unchanged marital relationship between parents, while six respondents reported a change in this relationship. All those who reported a change said it was for the worse, and one couple had ended up divorcing. Due to the small sample size, group differences were examined using the Mann-Whitney U-test. 
Parents whose child was predominantly at home felt more often that their parent-child relationship had deteriorated compared to parents whose child was predominantly in daycare $(\mathrm{U}=20.0, p=0.026)$. The children of all parents who reported on average a slight or significant deterioration in the parent-child relationship $(n=8)$ were mainly or completely at home. In contrast, none of the parents whose children were mainly or completely in daycare during the spring of $2020(n=7)$ reported deterioration in the parent-child relationship. There was no significant difference in mental strain between parents whose children were at home or in daycare. During the crisis, parents reported that children at home felt lonelier than before $(\mathrm{U}=11.0, p=0.001)$ compared to children who were in daycare all the time or for the most part of the spring of 2020. Whether the children were at home or in daycare was not associated with the children's physical symptoms, self-esteem, or negativity.

Parents with a worsened marital relationship felt more often that their relationship with their children had also deteriorated compared to parents with an unaffected relationship ( $\mathrm{U}=15.0, p=0.022)$. The status of the relationship had no effect on the parents' mental strain. Children whose parents' relationship had deteriorated were more likely to show more negativity $(\mathrm{U}=13.5, p=0.004)$ than children whose parents' relationship had remained unchanged. Changes in the parents' relationship had no statistically significant main effect on children's physical symptoms, self-esteem, or loneliness. Table 3 shows the group-specific descriptives for the variables.

Table 3. Parenthood and wellbeing of children while children were at home or in daycare and while the parents' marital relationship was unaffected or worsened during the restrictions. The variables receive values between 0 and 4 ( $4=\mathrm{Much}$ better than before/much more often than before/much higher than before). The significant differences in group comparisons are bolded and marked with asterisks. Only 20 parents of a total of 23 children answered the question regarding the status of the marital relationship.

\begin{tabular}{|c|c|c|c|c|c|}
\hline & All & Children at Home & $\begin{array}{l}\text { Children in } \\
\text { Daycare }\end{array}$ & $\begin{array}{c}\text { Unaffected Marital } \\
\text { Relationship }\end{array}$ & $\begin{array}{l}\text { Worsened Marital } \\
\text { Relationship }\end{array}$ \\
\hline Parents & $N=21$ & $n=14$ & $n=7$ & $n=14$ & $n=6$ \\
\hline $\begin{array}{l}{ }^{1} \text { Parent-child } \\
\text { relationship }\end{array}$ & $\begin{array}{c}M=1.75 \\
M D=2.00 \\
S D=0.57\end{array}$ & $\begin{aligned} * M & =1.57 \\
M D & =1.50 \\
S D & =0.62\end{aligned}$ & $\begin{array}{c}M=2.13 \\
M D=2.00 \\
S D=0.21\end{array}$ & $\begin{aligned} * M & =1.93 \\
M D & =2.00 \\
S D & =0.54\end{aligned}$ & $\begin{array}{c}M=1.29 \\
M D=1.25 \\
S D=0.43\end{array}$ \\
\hline Mental strain & $\begin{array}{c}M=2.26 \\
M D=2.36 \\
S D=0.59\end{array}$ & $\begin{array}{c}M=2.27 \\
M D=2.32 \\
S D=0.61\end{array}$ & $\begin{array}{c}M=2.30 \\
M D=2.53 \\
S D=0.64\end{array}$ & $\begin{array}{c}M=2.19, M D=2.24 \\
S D=0.63\end{array}$ & $\begin{array}{c}M=2.48 \\
M D=2.53 \\
S D=0.52\end{array}$ \\
\hline Children & $N=24$ & $n=17$ & $n=7$ & $n=16$ & $n=7$ \\
\hline $\begin{array}{l}\text { Physical } \\
\text { symptoms }\end{array}$ & $\begin{array}{c}M=1.07 \\
M D=1.33 \\
S D=0.89\end{array}$ & $\begin{array}{c}M=0.96 \\
M D=1.00 \\
S D=0.97\end{array}$ & $\begin{array}{c}M=1.33 \\
M D=1.33 \\
S D=0.64\end{array}$ & $\begin{array}{c}M=0.85, M D=.83 \\
\quad S D=0.87\end{array}$ & $\begin{array}{c}M=1.43 \\
M D=1.33 \\
S D=0.85\end{array}$ \\
\hline Self-esteem & $\begin{array}{c}M=2.12 \\
M D=2.00 \\
S D=0.35\end{array}$ & $\begin{array}{c}M=2.20 \\
M D=2.00 \\
S D=0.39\end{array}$ & $\begin{array}{c}M=1.95 \\
M D=2.00 \\
S D=0.13\end{array}$ & $\begin{array}{c}M=2.13, M D=2.00 \\
S D=0.36\end{array}$ & $\begin{array}{c}M=2.14 \\
M D=2.00 \\
S D=0.38\end{array}$ \\
\hline Negativity & $\begin{array}{c}M=1.54 \\
M D=1.64 \\
S D=0.53\end{array}$ & $\begin{array}{c}M=1.48 \\
M D=1.64 \\
S D=0.60\end{array}$ & $\begin{array}{c}M=1.69 \\
M D=1.82 \\
S D=0.29\end{array}$ & $\begin{array}{c}* * M=1.34 \\
M D=1.45 \\
S D=0.49\end{array}$ & $\begin{array}{c}M=1.94 \\
M D=2.09 \\
S D=0.40\end{array}$ \\
\hline My child felt alone & $\begin{array}{c}M=2.12 \\
M D=2.00 \\
S D=1.04\end{array}$ & $\begin{array}{c}* * * M=2.59 \\
M D=3.00 \\
S D=0.62\end{array}$ & $\begin{array}{c}M=1.00 \\
M D=1.00 \\
S D=1.00\end{array}$ & $\begin{array}{c}M=2.06, M D=2.00 \\
S D=1.00\end{array}$ & $\begin{array}{c}M=2.57 \\
M D=3.00 \\
S D=0.79\end{array}$ \\
\hline
\end{tabular}

${ }^{1}$ The included items were evaluated by 20 parents, 13 of them with children at home during restrictions and 5 of them with a worsened marital relationship. ${ }^{*}=p<0.05,{ }^{* *}=p<0.01,{ }^{* * *}=p<0.001$. 
Parental relationship's status or childcare arrangements were not associated with parents' assessments of their children's strengths and difficulties (SDQs), or the changes therein compared to pre-pandemic.

\section{Discussion}

A comparison between pandemic and pre-pandemic SDQ surveys found that, based on parental assessment, there had been no change in children's emotional problems, conduct disorders, peer problems, or hyperactivity. The results we obtained are in line or partly in line with the Canadian and U.S. studies $[15,18]$ and contradict those of Di Giorgio et al. [17] obtained in Italy. In addition, Gassman-Pines and colleagues [11] measured child uncooperativeness, which could be interpreted to correspond to SDQ's "conduct problems," and found no change in it either. None of the previous studies reviewed measured prosocial skills.

Differences in these outcomes may be due to, for example, cultural differences between countries or differences in the educational level and work situations of the families involved. As pointed out in a recent review [20], outcomes may also be affected, e.g., by pre-existing mental health conditions and family relationships which were not controlled for in our study. In terms of our own research, the comforting results related to the children's wellbeing may be due, at least in part, to the middle-class status of the families involved. The socio-economic profile of our sample families was high, and the economic situation, for example, had not worsened in most families. Parents of such families are presumably better able to protect their offspring from their own stress and anxiety. Particularly in well-off families, pre-school children did not appear to especially suffer from the downsizing of their everyday circles or the change in their routines. However, the prosocial behavior of children was rated worse than earlier by parents. This might mean that the stress the children have experienced during the quarantine has manifested itself predominately in prosocial skills. Another possible explanation is that when many parents saw their child more, they may have seen shortcomings in their children's behavior that had gone unnoticed in the past.

According to the KINDL questionnaire completed by their parents, the children experienced more loneliness than before, but otherwise they seemed mostly to do well during quarantine. On average, the children had fewer physical symptoms and their mood was more positive than before the lockdown. These results are supported by previous studies showing very few physical symptoms [12] or no decline in the mood [11] in children due to the pandemic. In addition, the self-esteem of almost all children was estimated to be equal to that in the past. The changes in children's physical symptoms correlated strongly with changes in the children's negativity; the fewer physical symptoms a child had, the more positive the mood she/he showed.

Examining the relationship between children and parents, a discrepancy was found in the results: the majority of parents responded, when asked directly, that the relationship had not changed during the exceptional period (17), or that it had even improved (3). However, based on a separate sum variable parent-child relationship, this was not the case; the relationship had on average deteriorated slightly. The parents' mental strain had a marginal correlation with the quality of parent-child relationship, parents' experiencing more mental strain demonstrating a worse parent-child relationship than their peers experiencing less mental strain. The discrepancy between the direct question and the statements that measure the parent-child relationship could be due to number of factors: some parents may be reluctant to think that the relationship with the child has worsened, and for this reason have reported no change in the relationship when asked directly. On the other hand, parents may not always recognize the deterioration in the relationship or may not interpret the question unambiguously, and for this reason problems in the parent-child relationship may be reflected in the sum variable measuring this relationship, rather than the direct question. 
Parents who participated in the study experienced, on average, slightly more mental strain during the exceptional circumstances than before, and this result is in alignment with U.S. studies showing an increase in mental strain under the crisis [11,12]. This is not unexpected, as at the time of the first lockdowns no-one knew how the situation was going to develop and how many people were endangered by the deadly virus. Furthermore, the parents' mental strain was marginally correlated with the quality of the parent-child relationship, which is in line with several previous studies [13,21,22]. One might conclude that the combination of work and childcare caused the parents stress, which was reflected in the parent-child relationship.

When evaluating the effects of the ECEC dropout and the possible effects of quarantine on the wellbeing of families, it is important to note that participation in ECEC was related to the parent-child relationship. If the child stayed at home during the lockdown, the parent-child relationship was on average worse than for those whose child attended early childhood education. In addition, the children who stayed home were reported to be lonelier than those who participated in ECEC. The results are intuitively understandable and in line with a recent study in which the pandemic-induced stress factors and parental anxiety and depression were associated with the burden of parenthood [13].

In our study, about one-third of the parents' marital relationships had declined. Our observation on the state of marital relationships supports Pietromonaco and Overall's view [23] that COVID-19-related stress is likely to increase harmful behavior in relationships, especially if the relationship carries previous risk factors in the form of social class, minority status, or psychological factors. Our results show that if the parents' relationship with each other was not thriving, the relationship with the child was worse than for those whose partnership remained unaffected. Although the children in our study were doing relatively well, the deterioration in the parents' marital relationship had some effects on the wellbeing of the children. Children whose parents' relationship had deteriorated were more likely to be negative compared to children whose parents' partnership was unchanged. The parents' relationship is a significant factor influencing both parenting [24] and the child's development [25]. Children typically hear disputes between their parents, but if they recur they can affect children's wellbeing. A change for the worse in marital relationships did not affect the children's physical symptoms, self-esteem, or loneliness.

The obvious shortcoming of our study is the small number of participants, which places significant limitations on the generalizability of the results. The number of parents who responded indicates that the sample focuses on families who were doing relatively well and who had significantly more mental and psychological resources at their disposal than those parents of about 60 families who did not respond to the questionnaires. Thus, it can be seen that our results mainly concern financially stable families, and the potentially very polarized effects of the pandemic were not reflected in our sample. It is very likely that the crisis has affected more negatively economically and socially vulnerable families [11] and supporting them via psychological and social programs will be of utmost importance. As Spiteri [4] points out, the crisis is also a children's rights crisis, and strong efforts are needed to support children living in vulnerable conditions. Although it is too early to draw conclusions on the effect of COVID-19 on children and families, some recent observations on the increase in children needing service from child protection authorities during and after the lockdown have also lead to changes in the public policy in Finland, with the highest priority being to avoid a lockdown of schools and ECEC centers [26,27].

Overall, our research showed that parents of families from fairly well-off socioeconomic backgrounds have experienced some increased mental strain during these exceptional circumstances. Children under school age have experienced some loneliness but have otherwise been generally well during the first months of the pandemic. During the crisis, some parents' marital relationships have suffered, and this has likely had a negative impact on some parent-child relationships and on children's mood. Since two-thirds of the children were at home during the exceptional period, daycare appears to have been a protective factor in the parent-child relationship during the pandemic. The children's 
participation in early childhood education improved the parent-child relationship. The reason for this may lie in the challenges of many parents trying to cope with work and childcare at the same time. However, our data were limited and thus our results should be interpreted with caution.

Supplementary Materials: The following are available online at https: / www.mdpi.com/article/ 10.3390/educsci11080435/s1, Table S1: List of the responded questionnaires for each child. Questionnaire S2: The pandemic-related questionnaire.

Author Contributions: Conceptualization, M.K. and T.L.; Methodology, T.L. and M.K.; Validation, T.L. and M.K.; Formal Analysis, T.L.; Investigation, T.L.; Data Curation, T.L.; Writing-Original Draft Preparation, T.L. and M.K.; Writing-Review \& Editing, T.L. and M.K.; Project Administration, T.L. and M.K.; Funding Acquisition, M.K. Both authors have read and agreed to the published version of the manuscript.

Funding: This research was funded by Svenska Kulturfonden, Finland.

Institutional Review Board Statement: The study was conducted according to the guidelines of the Declaration of Helsinki and approved by the University of Helsinki Ethical Review Board in the Humanities and Social and Behavioural Sciences, in Helsinki, Finland (65/2019; approved 6 November 2019).

Informed Consent Statement: Informed consent was obtained from all subjects involved in the study.

Data Availability Statement: The data presented in this study are available on request from the corresponding author. The data are not publicly available due to the small sample size which might enable the disclosure of sensitive information about individual children and families.

Acknowledgments: The authors would like to thank all the ECEC personnel for their contribution to the research, the children, and families for participating, and the research assistants Minea An-tila, Lina-Lotta Kauhanen and Madeleine Rusk for their help in collecting the data.

Conflicts of Interest: The authors declare no conflict of interest.

\section{References}

1. Unesco. One Year into COVID-19 Education Disruption: Where Do We Stand? Press Release. 2021. Available online: https: / / en.unesco.org/news/one-year-covid-19-education-disruption-where-do-we-stand (accessed on 22 March 2021).

2. Unesco. UNESCO Figures Show Two Thirds of an Academic Year Lost on Average Worldwide Due to Covid-19 School Closures. Press Release. 2021. Available online: https:/ / en.unesco.org/news/unesco-figures-show-two-thirds-academic-yearlost-average-worldwide-due-covid-19-school (accessed on 22 March 2021).

3. Unesco. The Impact of COVID-19 on ECCE Sector: Lesson Learned and Promising Practices from the Asia-Pacific. 2020. Available online: https:/ / en.unesco.org/sites/default/files/unesco-covid-19_ed-webinar-14-unesco-bangkok.pdf (accessed on 22 March 2021).

4. Spiteri, J. The impact of covid-19 on the progress towards sustainable development goal 4 in the early years: A rapid review. In Covid-19: Paving the Way for a More Sustainable World; Filho, W.L., Ed.; Springer: Cham, Switzerland, 2021. [CrossRef]

5. Regional State Administrative Agency. Kuntakysely: Oppimisen Tukeen ja Oppilashuoltoon Täytyy Panostaa Myös Poikkeusoloissa. News. 2020. Available online: https://minedu.fi/-/kuntakysely-oppimisen-tukeen-ja-oppilashuoltoon-taytyypanostaa-myos-poikkeusoloissa (accessed on 13 April 2021).

6. Kang, Y.Q.; Lim, T.S.H.; Ragen, E.S.; Tan, M.Y.; Aishworiya, R. Managing children's anxiety during covid-19 pandemic: Strategies for providers and caregivers. Front. Psychiatry 2020, 11, 552823. [CrossRef] [PubMed]

7. Prime, H.; Wade, M.; Browne, D.T. Risk and resilience in family well-being during the COVID-19 pandemic. Am. Psychol. 2020, 75, 631-643. [CrossRef] [PubMed]

8. Spiteri, J. Quality early childhood education for all and the Covid-19 crisis: A viewpoint. Prospects 2021. [CrossRef] [PubMed]

9. University of Jyväskylä. Vanhemmat Kokevat COVID-19-Ajan Eri Tavoin-Jotkut Haluavat Jäädä Poikkeusaikaan. Research News. 2020. Available online: https:/ / www.jyu.fi/fi/ajankohtaista/arkisto/2020/05/vanhemmat-kokevat-covid-19-ajan-eritavoin-2013-jotkut-haluavatjaada-poikkeusaikaan (accessed on 18 March 2021).

10. Parikka, S.; Ikonen, J.; Koskela, T.; Hedman, L.; Kilpeläinen, H.; Aalto, A.-M.; Sainio, P.; Ilmarinen, K.; Holm, M.; Lundqvist, A. Koronan Vaikutukset Vaihtelevat Alueittain—Eroja Myös Ikääntyneillä Sekä Toimintarajoitteisilla Verrattuna Muuhun Väestöön. Preliminary Results from National FinSote Research. 2020. Available online: http:/ /terveytemme.fi/finsote/korona2020/index. html (accessed on 18 March 2021).

11. Gassman-Pines, A.; Ananat, E.O.; Fitz-Henley, J. COVID-19 and Parent-Child Psychological Well-being. Pediatrics 2020, 146, e2020007294. [CrossRef] [PubMed] 
12. Patrick, S.; Henkhaus, L.; Zickafoose, J.; Lovell, K.; Halvorson, A.; Loch, S.; Letterie, M.; Davis, M. Well-being of parents and children during the covid-19 pandemic: A national survey. Pediatrics 2020, 146, e2020016824. [CrossRef] [PubMed]

13. Brown, S.M.; Doom, J.R.; Lechuga-Peña, S.; Watamura, S.E.; Koppels, T. Stress and parenting during the global COVID-19 pandemic. Child Abus. Negl. 2020, 110, 104699. [CrossRef] [PubMed]

14. Goodman, R. Psychometric properties of the strengths and difficulties questionnaire. J. Am. Acad. Child Adolesc. Psychiatry 2001, 40, 1337-1345. [CrossRef] [PubMed]

15. Romero, E.; López-Romero, L.; Domínguez-Álvarez, B.; Villar, P.; Gómez-Fraguela, J.A. Testing the effects of COVID-19 confinement in Spanish children: The role of parents' distress, emotional problems and specific parenting. Int. J. Environ. Res. Public Health 2020, 17, 6975. [CrossRef]

16. Gioia, G.A.; Espy, K.A.; Isquith, P.K. Behavior rating inventory of executive function-preschool version. In Psychol Assess Resour; PAR: Odessa, FL, USA, 2003.

17. Di Giorgio, E.; Di Riso, D.; Mioni, G.; Cellini, N. The interplay between mothers' and children behavioral and psychological factors during COVID-19: An Italian study. Eur. Child Adolesc. Psychiatry 2020. [CrossRef] [PubMed]

18. Cost, K.T.; Crosbie, J.; Anagnostou, E.; Birken, C.S.; Charach, A.; Monga, S.; Kelley, E.; Nicolson, R.; Maguire, J.L.; Burton, C.L.; et al. Mostly worse, occasionally better: Impact of COVID-19 pandemic on the mental health of Canadian children and adolescents. Eur. Child Adolesc. Psychiatry 2021. [CrossRef] [PubMed]

19. Ravens-Sieberer, U.; Bullinger, M. Assessing health related quality of life in chronically ill children with the German KINDL: First psychometric and content-analytical results. Qual. Life Res. 1998, 4, 399-407. [CrossRef] [PubMed]

20. Spiteri, J. The impact of the COVID-19 pandemic on children's mental health and wellbeing, and beyond: A scoping review. J. Child. Educ. Soc. 2021, 2, 126-138. [CrossRef]

21. Calvano, C.; Engelke, L.; Di Bella, J.; Kindermann, J.; Renneberg, B.; Winter, S. Families in the COVID-19 pandemic: Parental stress, parent mental health and the occurrence of adverse childhood experiences-results of a representative survey in Germany. Eur. Child Adolesc. Psychiatry 2021. [CrossRef]

22. Chung, G.; Lanier, P.; Wong, P.Y.J. Mediating effects of parental stress on harsh parenting and parent-child relationship during coronavirus (covid-19) pandemic in Singapore. J. Fam. Violence 2020. [CrossRef] [PubMed]

23. Pietromonaco, P.R.; Overall, N.C. Applying relationship science to evaluate how the COVID-19 pandemic may impact couples' relationships. Am. Psychol. 2020, 76, 438-450. [CrossRef] [PubMed]

24. Christopher, C.; Umemura, T.; Mann, T.; Jacobvitz, D.; Hazen, N. Marital quality over the transition to parenthood as a predictor of coparenting. J. Child Fam. 2015, 24, 3636-3651. [CrossRef]

25. Knopp, K.; Rhoades, G.K.; Allen, E.S.; Parsons, A.; Ritchie, L.L.; Markman, H.J.; Stanley, S.M. Within-and between-family associations of marital functioning and child well-being. J. Marriage Fam. 2017, 79, 451-461. [CrossRef] [PubMed]

26. Eriksson, P.; Nelimarkka, S.; Paasivirta, A.; Tiili, A.; Yliruka, L. Koronan Vaikutukset Lastensuojeluun—Osa 2. THL—Tutkimuksesta Tiiviisti 16. 2021. Available online: https:/ / www.julkari.fi/bitstream/handle/10024/141537/URN_ISBN_978-952-343-644-2.pdf? sequence $=1$ \&isAllowed $=y$ (accessed on 13 August 2021).

27. Tiili, A.; Paasivirta, A.; Kuokkanen, J.; Eriksson, P.; Nelimarkka, S. Koronan Vaikutukset Lastensuojeluun. THL—Tutkimuksesta Tiiviisti, 34. 2020. Available online: https://www.julkari.fi/bitstream/handle/10024/140789/TUTI2020_034_Koronan\%20 vaikutukset\%20lastensuojeluun_korjattu_s.pdf?sequence=4\&isAllowed=y (accessed on 13 August 2021). 